\title{
Genetic variation of bovine leukemia virus (BLV) after replication in cell culture and experimental animals
}

\author{
M.F. Camargos ${ }^{2}$, D.S. Rajão ${ }^{1}$, R.C. Leite ${ }^{1}$, D. Stancek ${ }^{1}$, M.B. Heinemann ${ }^{1}$ \\ and J.K.P. Reis ${ }^{1}$ \\ ${ }^{1}$ Laboratório de Retroviroses, Departamento de Medicina Veterinária Preventiva, \\ Escola de Veterinária, Universidade Federal de Minas Gerais, \\ Belo Horizonte, MG, Brasil \\ ${ }^{2}$ Laboratório Nacional Agropecuário, Ministério da Agricultura, \\ Pecuária e Abastecimento, Pedro Leopoldo, MG, Brasil \\ Corresponding author: J.K.P. Reis \\ E-mail: jenner@ufmg.br
}

Genet. Mol. Res. 13 (1): 1717-1723 (2014)

Received September 15, 2013

Accepted November 12, 2013

Published January 22, 2014

DOI http://dx.doi.org/10.4238/2014.January.22.11

\begin{abstract}
This article reports the selection of bovine leukemia virus (BLV) variants after continuous passage in cell lines or experimental animals. Two wild BLV strains isolated from 2 naturally infected Holstein dairy cows in Brazil (cow codes: 485 and 141) were used for the experimental infection of 1 sheep and FLK cells, and 1 rabbit and CC81 cells. Viral DNA was isolated several months after infection, and env gene nucleotide and amino acid sequences of the "passaged" variants were compared against the 2 original infecting wild strains. The sequences of the original infecting wild strains were not recovered after their replication in the cell lines or experimental animals. These results indicate that genetic variation occurred after BLV replication in vivo and in vitro, with new variants being selected.
\end{abstract}

Key words: Bovine leukemia virus; Genetic variation; Cell culture; Experimental infection 


\section{INTRODUCTION}

Bovine leukemia virus (BLV) is an oncogenic virus that belongs to the Deltaretrovirus genus of the Retroviridae family, and is closely related to the Human T-cell Leukemia virus (HTLV) (Goff, 2007). The major viral targets are B-lymphocytes, which express surface immunoglobulin M (Schwartz et al., 1994; Mirsky et al., 1996); however, BLV has been reported to infect other cell lineages in vivo, such as $\mathrm{CD} 8^{+} \mathrm{T}$ cells, monocytes, and granulocytes (Schwartz et al., 1994; Domenech et al., 2000). In addition, BLV has been found to infect a wide variety of cells in vitro, such as fetal lamb kidney (FLK), feline fibroblast (CC81), Madin-Darby bovine kidney (MDBK), baby hamster kidney (BHK), and human epithelial cervical cancer (HeLa) (Graves and Ferrer, 1976; Ferrer et al., 1981; Altaner et al., 1989; Inabe et al., 1998). It seems that the BLV receptor is not restricted to a specific cell population, but that it is broadly expressed (Schwartz et al., 1994).

Although bovines are the natural hosts for BLV, the experimental infection of many species has been reported, including rabbits (Onuma et al., 1990), rats (Boris-Lawrie et al., 1997), chickens (Altanerova et al., 1990), pigs (Mammerickx et al., 1981), goats (Olson et al., 1981), and sheep, with sheep serving as a good experimental model for BLV pathogenicity studies (Brandon et al., 1991; Kabeya et al., 2001).

The BLV envelope (env) gene encodes transmembrane (gp30) and surface (gp51) glycoproteins, with gp51 being known to play an important role for viral infection (Gillet et al., 2007). In contrast to that observed for other retroviruses, including Human Immunodeficiency virus (HIV) (Price et al., 1998) and equine infectious anemia (EIAV) (Craigo et al., 2009), the BLV envelope gene exhibits low levels of variation (Mamoun et al., 1990; Willems et al., 1995), because BLV env gene sequence substitutions are usually silent (Dube et al., 2000; Camargos et al., 2002). However, recent studies have indicated the circulation of 7 different BLV genotypes that might be associated with the geographic origin of the isolates, contradicting previous assumptions (Camargos et al., 2007; Zhao and Buehring, 2007; Moratorio et al., 2010).

In the present study, we evaluated the selection of BLV variants after continuous passage in 2 different cell lines and after the experimental infection of 2 different animal species.

\section{MATERIAL AND METHODS}

The virus samples used in this study originated from BLV-infected peripheral blood mononuclear cells (PBMC) obtained from 2 clinically healthy BLV seropositive Holstein dairy cows (cow codes: 141 and 485), from Minas Gerais State, Brazil. Blood samples were collected in tubes containing EDTA, and PBMC were obtained from buffy coat by Ficoll (Sigma Aldrich, Mississauga, Ontario, CA), following manufacturer protocols.

One 6-month-old Merino sheep tested negative for BLV infection was inoculated intravenously with $2 \mathrm{~mL}$ BLV-infected PBMC from Cow 485, and $1 \mathrm{New}$ Zealand rabbit $(\sim 1$ $\mathrm{kg}$ ) was inoculated intramuscularly with $0.5 \mathrm{~mL}$ BLV-infected PBMC from Cow 141. Blood samples were collected in tubes containing EDTA at 210 and 425 days post-inoculation (dpi) from the infected sheep and rabbit, respectively. The 2 animals were kept under controlled conditions throughout the study. Neither experimental animal showed clinical signs of BLV during the study period. This study was in accordance with the standards of Universidade Federal de Minas Gerais Animal Experimentation Ethics Committee. 
FLK and CC 81 cells were cultivated at $37^{\circ} \mathrm{C}$ in a $5 \% \mathrm{CO}_{2}$ atmosphere in minimal essential medium (MEM), supplemented with 5\% fetal calf serum (FBS) and antibiotics (200 U/ $\mathrm{mL}$ penicillin, $200 \mu \mathrm{g} / \mathrm{mL}$ streptomycin, and $1.25 \mu \mathrm{g} / \mathrm{mL}$ amphotericin $\mathrm{B})$. The cell lines were free of bovine viral diarrhea virus (BVDV). Virus-free FLK monolayers were inoculated with $0.5 \mathrm{~mL}$ BLV-infected PBMC $\left(5 \times 10^{6}\right.$ leucocytes $\left./ \mathrm{mL}\right)$ isolated from Cow 485, and virus-free CC81 monolayers were inoculated with $0.5 \mathrm{~mL}$ of BLV-infected PBMC isolated from Cow 141. Cells were re-plated $24 \mathrm{~h}$ after infection, and serially split every 4 days. Supernatant samples were harvested after 30 and 25 passages for FLK and CC81, respectively. Syncytium formation was observed in both infected cell lines, and BLV gp-51 was detected by indirect immunofluorescence, as previously described by Ferrer et al. (1981).

Proviral DNA was obtained from the whole blood of originally infected cows and experimentally infected animals and from the infected cell cultures after 2 freeze-thaw cycles using the GFX Genomic Blood DNA Purification Kit ${ }^{\circledR}$ (Amersham Pharmacia Biotech, Piscataway, NJ, USA). Forward env 5128 (5'-GGCCATGGTCACATATGATTG-3') and reverse env 5627 (5'-CGTTGCCTTGAGAAACATTGAAC-3') primers were constructed to amplify a 521-bp fragment of the gp51 glycoprotein, as previously described by Sagata et al. (1985). PCR was performed, as previously described by Camargos et al. (2007).

The PCR products were purified by Wizard PCR Preps DNA Purification System Kit ${ }^{\circledR}$ (Promega, Madison, Wi, USA), and sequenced bi-directionally by the BigDye Terminator v3.1 Cycle Sequencing Kit (Applied Biosystems, Foster City, CA, USA) using the A.L.F. DNA Sequencer (Pharmacia, Uppsala, Sweden), edited in Mega 5.01 and aligned using Clustal W (Tamura et al., 2011). BLV gp51 env sequences from Brazilian strains previously deposited in the GenBank were used for the phylogenetic analysis (Brazil 1, 2, and 3, accession numbers AF399702-AF399704). Phylogenetic analysis was conducted by the neighbor-joining method with the Kimura model (Saitou and Nei, 1987) in the MEGA 5.01 software (Tamura et al., 2011). Bootstrap tests of 1000 replicates were used.

\section{RESULTS AND DISCUSSION}

The BLV env gene of wild and passaged strains was partially sequenced (408 nt; 5205-5613), coding for 136 amino acids (aa). None of the original wild BLV variants (Cow 485 or Cow 141) was recovered after the infection of the sheep and the rabbit, or replication in FLK and CC81 cells. In the past, the BLV env gene mutation rate was assumed to be low, even after the experimental passage of the provirus in vivo (Juliarena et al., 2013). Even though BLV has been shown to have lower genetic variation compared to other retroviruses (Price et al., 1998; Craigo et al., 2009), and to contain highly conserved regions involved in the cell-virus interaction (Coulston et al., 1990; Mamoun et al., 1990), our results support recent studies reporting about the genetic variation of BLV and the circulation of 7 genetic distinct groups (Zhao and Buehring, 2007; Moratorio et al., 2010), of which 4 were detected in Brazil (Camargos et al., 2002, 2007).

Variant Sheep and FLK presented homologous nucleotide sequences, and differed from the original infecting wild strain isolated from Cow 485 (Figure 1). This result indicates the selection of homologous mutants because of the presence of the same receptors on the cellular membranes of the sheep cells in vivo and of the FLK cells in vitro, which originated from fetal lamb kidney. Surprisingly, these 2 variants were clustered with the wild strain Cow 
141, instead of Cow 485 (Figure 2), which indicates the occurrence of mixed infection in the naturally infected cow, which had a closely related strain to that of Cow 141. Both the variants in the rabbit and CC81 differed considerably to one another and to the original infecting wild strain isolated from Cow 141 (Figure 1). A higher number of mutations were observed in the sequences after replication in rabbit and feline CC81 cells compared to the ones that passaged in sheep and ovine cells. This difference reflects the genetic proximity in the cellular receptors of different ruminant species. Nucleotide sequences of the rabbit and CC81 variants showed high homology with the Brazil 3 and Brazil 1 sequences, respectively (Figure 2). This homology might be the result of the selection of mutants that might be predecessors of the Brazil 1 and 3 variants in the infected leucocytes of cow 141. It has been suggested that env proviral sequences from different locations might be classified into groups (Camargos et al., 2002; Zhao and Buehring, 2007). Furthermore, the presence of BLV different groups in one geographical area has been reported before (Camargos et al., 2007; Zhao and Buehring, 2007; Moratorio et al., 2010), which might explain how different strains possibly infected the cows studied.

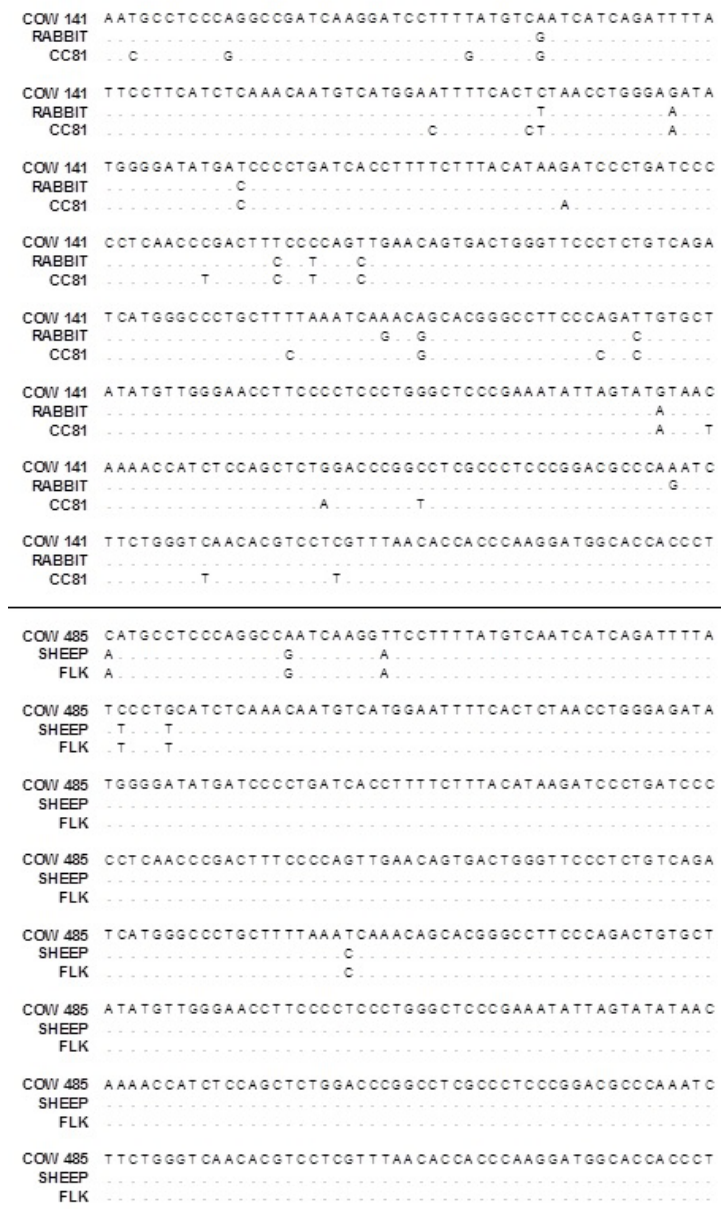

Figure 1. Nucleotide sequence alignment of the partial BLV env gene of wild and passaged Brazilian BLV strains. 


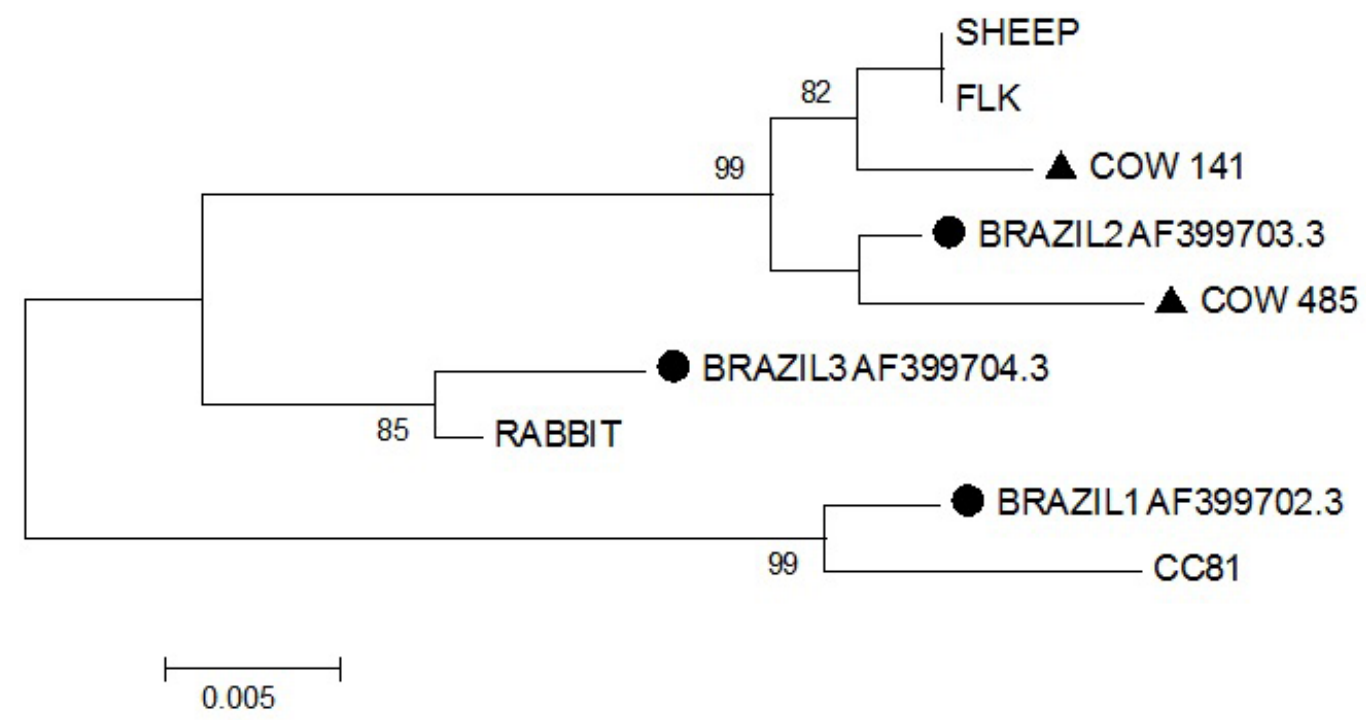

Figure 2. Phylogenetic tree of the partial BLV env gene (408 nt) constructed by the neighbor-joining method. The numbers shown at the nodes of the genetic clusters represent the bootstrap values for 1000 replicates. Triangles $=$ wild strains collected from BLV infected dairy cows; circles = Brazilian strains previously deposited in GenBank.

Experimental variant gp51 sequences showed some amino acid substitutions compared to the original wild strains, with these sequences being mainly located in the second neutralizing domain (Figure 3), which is related to T-cell proliferation in infected cows (Callebaut et al., 1993). The amino acid substitution N107D observed in both the rabbit and CC81 strains is located in a region associated with receptor binding (Gatot et al., 2002), and might influence virus fusion and infectivity. These amino acid substitutions might cause antigenic differences, reducing the efficiency of diagnostic methods and failure to detect infected animals, mainly through serological techniques (Fechner et al., 1997).

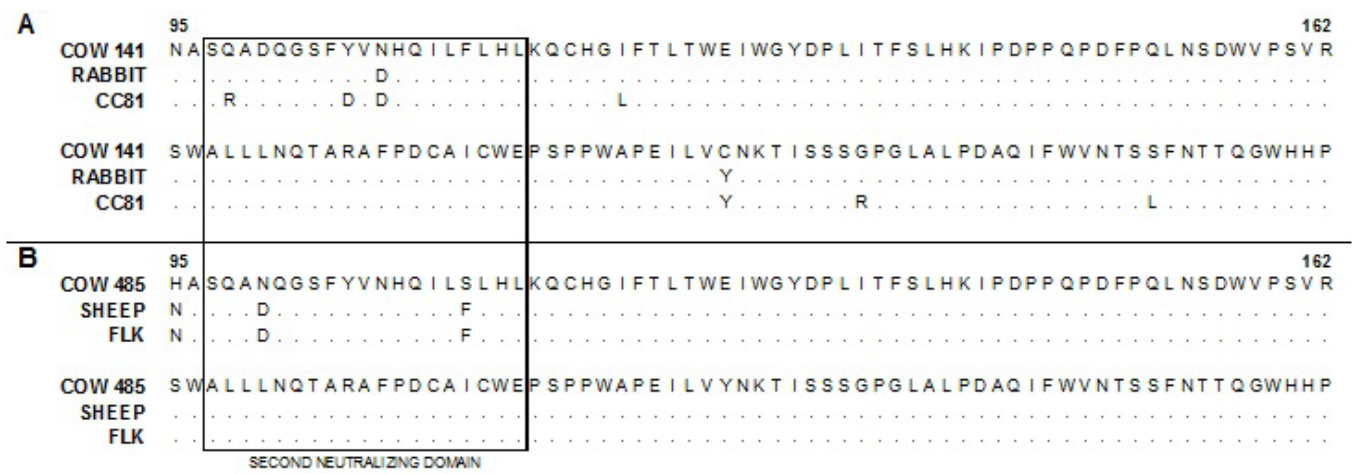

Figure 3. Amino acid sequence alignment of the partial BLV env gp51 glycoprotein of wild and passaged Brazilian BLV strains. A. Alignment for Cow 141 and its passage strains; B. alignment for Cow 485 and its passage strains. The gp51 second neutralizing domain (Callebaut et al., 1993) is shown by a box. 
In this study, 2 wild BLV strains isolated from naturally infected cows in Brazil were used for the experimental infection of 2 different animal species and 2 different cell lines, for which the env gene nucleotide and amino acid sequences were compared. Because of the specific conditions provided by different cell systems, a selection of various mutants occurred, resulting in the recovery of BLV variants that differed to the original wild strains. A combination of in vitro and in vivo operating mechanisms might be involved in mutant selection, such as receptor restriction, genetic control, and other less known factors. Our study provides a novel insight about how different cellular mechanisms might interfere in BLV replication (especially for $e n v$ gene proteins), which are critical for viral infection cellular tropism.

\section{ACKNOWLEDGMENTS}

The authors thank CNPq, FAPEMIG, INCT-Pecuária, and Pro-Reitoria de Pesquisa of UFMG for financial support. The authors thank Dr. Zamecník from Institute of Virolgy, Bratislava, Slovakia, and Dr. Altaner from Institute of Experimental Oncology, Bratislava, Slovakia for supplying cell lines.

\section{REFERENCES}

Altaner C, Altanerová V, Bán J, Niwa O, et al. (1989). Human cells of neural origin are permissive for bovine leukemia virus. Neoplasma 36: 691-695.

Altanerova V, Ban J, Kettmann R and Altaner C (1990). Induction of leukemia in chicken by bovine leukemia virus due to insertional mutagenesis. Arch. Geschwulstforsch 60: 89-96.

Boris-Lawrie K, Altanerova V, Altaner C, Kucerova L, et al. (1997). In vivo study of genetically simplified bovine leukemia virus derivatives that lack tax and rex. J. Virol. 71: 1514-1520.

Brandon RB, Naif H, Daniel RC and Lavin MF (1991). Early detection of bovine leukosis virus DNA in infected sheep using the polymerase chain reaction. Res. Vet. Sci. 50: 89-94.

Callebaut I, Voneche V, Mager A, Fumiere O, et al. (1993). Mapping of B-neutralizing and T-helper cell epitopes on the bovine leukemia virus external glycoprotein gp51. J. Virol. 67: 5321-5327.

Camargos MF, Stancek D, Rocha MA, Lessa LM, et al. (2002). Partial sequencing of env gene of bovine leukaemia virus from Brazilian samples and phylogenetic analysis. J. Vet. Med. B Infect. Dis. Vet. Public Health 49: 325-331.

Camargos MF, Pereda A, Stancek D, Rocha MA, et al. (2007). Molecular characterization of the env gene from Brazilian field isolates of Bovine leukemia virus. Virus Genes 34: 343-350.

Coulston J, Naif H, Brandon R, Kumar S, et al. (1990). Molecular cloning and sequencing of an Australian isolate of proviral bovine leukaemia virus DNA: comparison with other isolates. J. Gen. Virol. 71 (Pt 8): 1737-1746.

Craigo JK, Barnes S, Zhang B, Cook SJ, et al. (2009). An EIAV field isolate reveals much higher levels of subtype variability than currently reported for the equine lentivirus family. Retrovirology 6: 95.

Domenech A, Goyache J, Llames L, Jesus PM, et al. (2000). In vitro infection of cells of the monocytic/macrophage lineage with bovine leukaemia virus. J. Gen. Virol. 81: 109-118.

Dube S, Dolcini G, Abbott L, Mehta S, et al. (2000). The complete genomic sequence of a BLV strain from a Holstein cow from Argentina. Virology 277: 379-386.

Fechner H, Blankenstein P, Looman AC, Elwert J, et al. (1997). Provirus variants of the bovine leukemia virus and their relation to the serological status of naturally infected cattle. Virology 237: 261-269.

Ferrer JF, Cabradilla C and Gupta P (1981). Use of a feline cell line in the syncytia infectivity assay for the detection of bovine leukemia virus infection in cattle. Am. J. Vet. Res. 42: 9-14.

Gatot JS, Callebaut I, Van LC, Demonte D, et al. (2002). Bovine leukemia virus SU protein interacts with zinc, and mutations within two interacting regions differently affect viral fusion and infectivity in vivo. J. Virol. 76: 7956-7967.

Gillet N, Florins A, Boxus M, Burteau C, et al. (2007). Mechanisms of leukemogenesis induced by bovine leukemia virus: prospects for novel anti-retroviral therapies in human. Retrovirology 4: 18.

Goff SP (2007). Retroviridae: The Retroviruses and Their Replication. In: Fields Virology (Knipe DM and Howley PM, eds.). Lippincott Williams and Wilkins, Philadelphia, 1999-2069. 
Graves DC and Ferrer JF (1976). In vitro transmission and propagation of the bovine leukemia virus in monolayer cell cultures. Cancer Res. 36: 4152-4159.

Inabe K, Ikuta K and Aida Y (1998). Transmission and propagation in cell culture of virus produced by cells transfected with an infectious molecular clone of bovine leukemia virus. Virology 245: 53-64.

Juliarena MA, Lendez PA, Gutierrez SE, Forletti A, et al. (2013). Partial molecular characterization of different proviral strains of bovine leukemia virus. Arch. Virol. 158: 63-70.

Kabeya H, Fukuda A, Ohashi K, Sugimoto C, et al. (2001). Tumor necrosis factor alpha and its receptors in experimentally bovine leukemia virus-infected sheep. Vet. Immunol. Immunopathol. 81: 129-139.

Mammerickx M, Portetelle D and Burny A (1981). Experimental cross-transmissions of bovine leukemia virus (BLV) between several animal species. Zentralbl. Veterinarmed. B 28: 69-81.

Mamoun RZ, Morisson M, Rebeyrotte N, Busetta B, et al. (1990). Sequence variability of bovine leukemia virus env gene and its relevance to the structure and antigenicity of the glycoproteins. J. Virol. 64: 4180-4188.

Mirsky ML, Olmstead CA, Da Y and Lewin HA (1996). The prevalence of proviral bovine leukemia virus in peripheral blood mononuclear cells at two subclinical stages of infection. J. Virol. 70: 2178-2183.

Moratorio G, Obal G, Dubra A, Correa A, et al. (2010). Phylogenetic analysis of bovine leukemia viruses isolated in South America reveals diversification in seven distinct genotypes. Arch. Virol. 155: 481-489.

Olson C, Kettmann R, Burny A and Kaja R (1981). Goat lymphosarcoma from bovine leukemia virus. J. Natl. Cancer Inst. 67: 671-675.

Onuma M, Wada M, Yasutomi Y, Yamamoto M, et al. (1990). Suppression of immunological responses in rabbits experimentally infected with bovine leukemia virus. Vet. Microbiol. 25: 131-141.

Price DA, Meier UC, Klenerman P, Purbhoo MA, et al. (1998). The influence of antigenic variation on cytotoxic T lymphocyte responses in HIV-1 infection. J. Mol. Med. 76: 699-708.

Sagata N, Yasunaga T, Tsuzuku-Kawamura J, Ohishi K, et al. (1985). Complete nucleotide sequence of the genome of bovine leukemia virus: its evolutionary relationship to other retroviruses. Proc. Natl. Acad. Sci. U. S. A. 82: 677-681.

Saitou N and Nei M (1987). The neighbor-joining method: a new method for reconstructing phylogenetic trees. Mol. Biol. Evol. 4: 406-425.

Schwartz I, Bensaid A, Polack B, Perrin B, et al. (1994). In vivo leukocyte tropism of bovine leukemia virus in sheep and cattle. J. Virol. 68: 4589-4596.

Tamura K, Peterson D, Peterson N, Stecher G, et al. (2011). MEGA5: molecular evolutionary genetics analysis using maximum likelihood, evolutionary distance, and maximum parsimony methods. Mol. Biol. Evol. 28: 2731-2739.

Willems L, Kerkhofs P, Burny A, Mammerickx M, et al. (1995). Lack of LTR and ENV genetic variation during bovine leukemia virus-induced leukemogenesis. Virology 206: 769-772.

Zhao X and Buehring GC (2007). Natural genetic variations in bovine leukemia virus envelope gene: possible effects of selection and escape. Virology 366: 150-165. 